\section{introducción}

Ligera descripción de la gran cuenca hullera de carbón pardo, de Victoria (Australia).

Esta inmensa cuenca carbonífera está situada a unos $150 \mathrm{~km}$ de Melbourne, estado de Victoria, y en la región denominada el Valle del río La. trobe. Se cree que esta cuenca es la mayor del mundo en su género. Estos yacimientos se extienden en una longitud de unos $65 \mathrm{~km}$ y una anchura que varía de 8 a $16 \mathrm{~km}$. En un cierto lugar de esta zona, y a unos $27 \mathrm{~m}$ de profundidad, se ha perforado una capa de unos $230 \mathrm{~m}$ de potencia, lo que, innegablemente, hace de ella la mayor del mundo.

Al crearse en 1919 la Comisión Nacional de Electricidad, se previó la construcción de la primera Central a pie de mina para el año 1923, con una capacidad inicial de $50.000 \mathrm{~kW}$ de potencia.

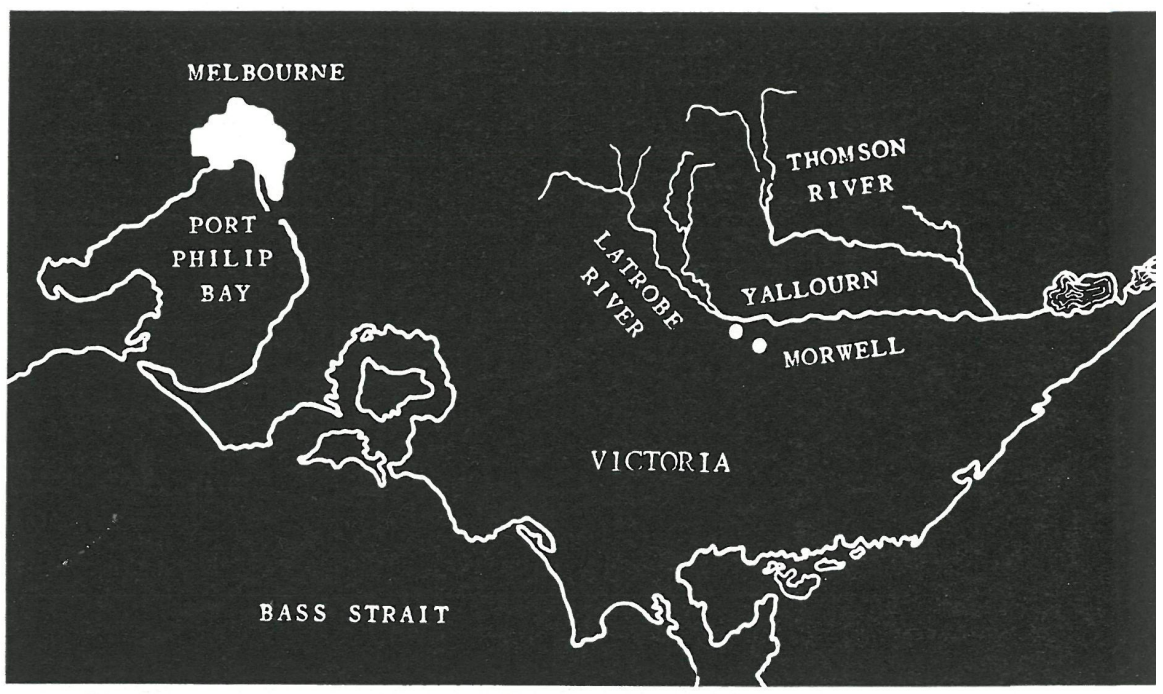

\title{
centrales térmicas a pie de mina
}

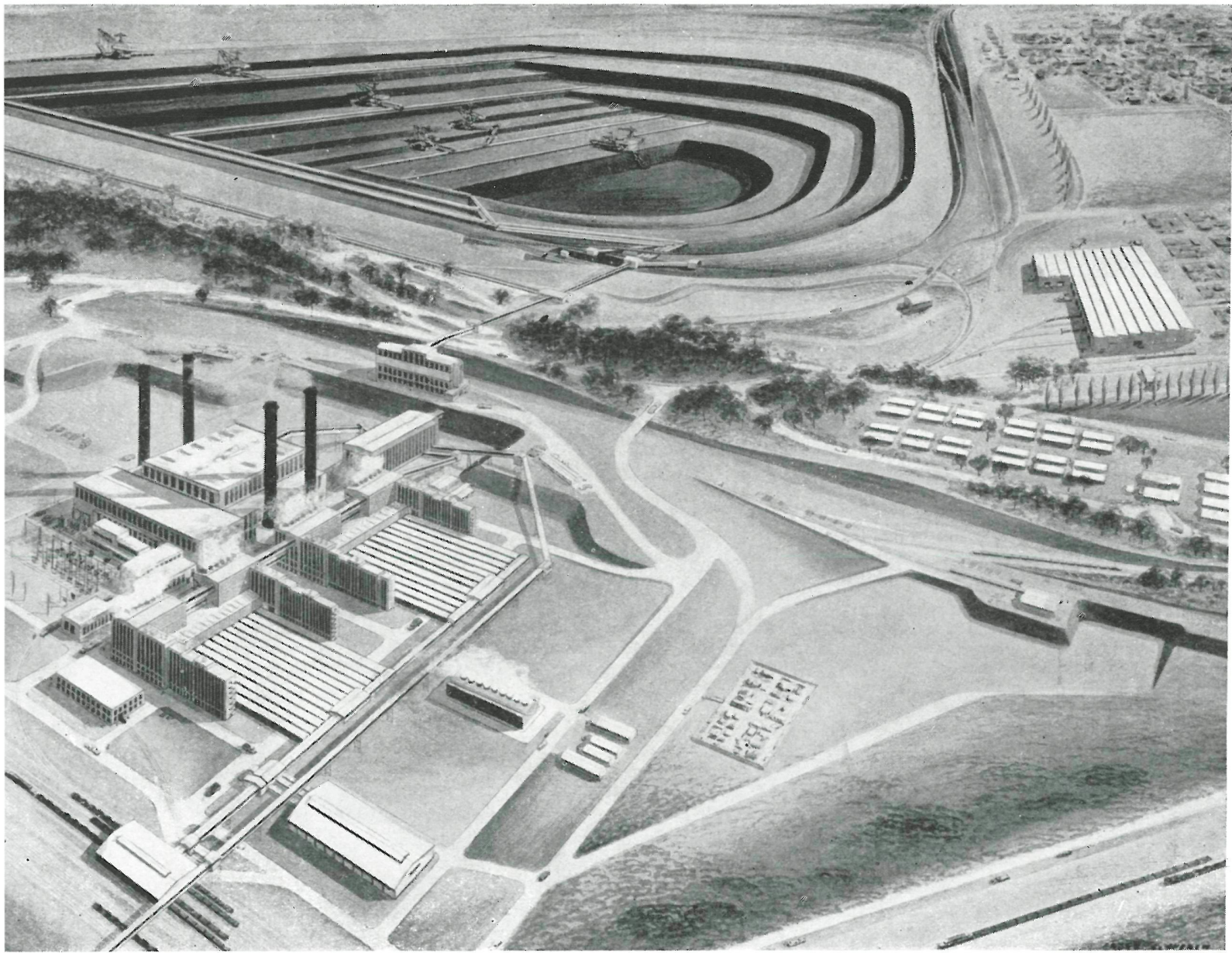

$592-1$ 


\section{El coto Yallourn a cielo abierto}

Este nombre, con que se designa la actual explotación de la cuenca carbonífera a cielo abierto, se deriva de dos palabras aborígenes que significan combustible pardo. Esta explotación en cantera se ha mecanizado de tal forma que permite la explotación a cielo abierto de una capa de $60 \mathrm{~m}$ de potencia, extendida en no menos de una extensión de $9 \mathrm{~km}$ de diámetro, con una producción anual de 10 millones de toneladas.

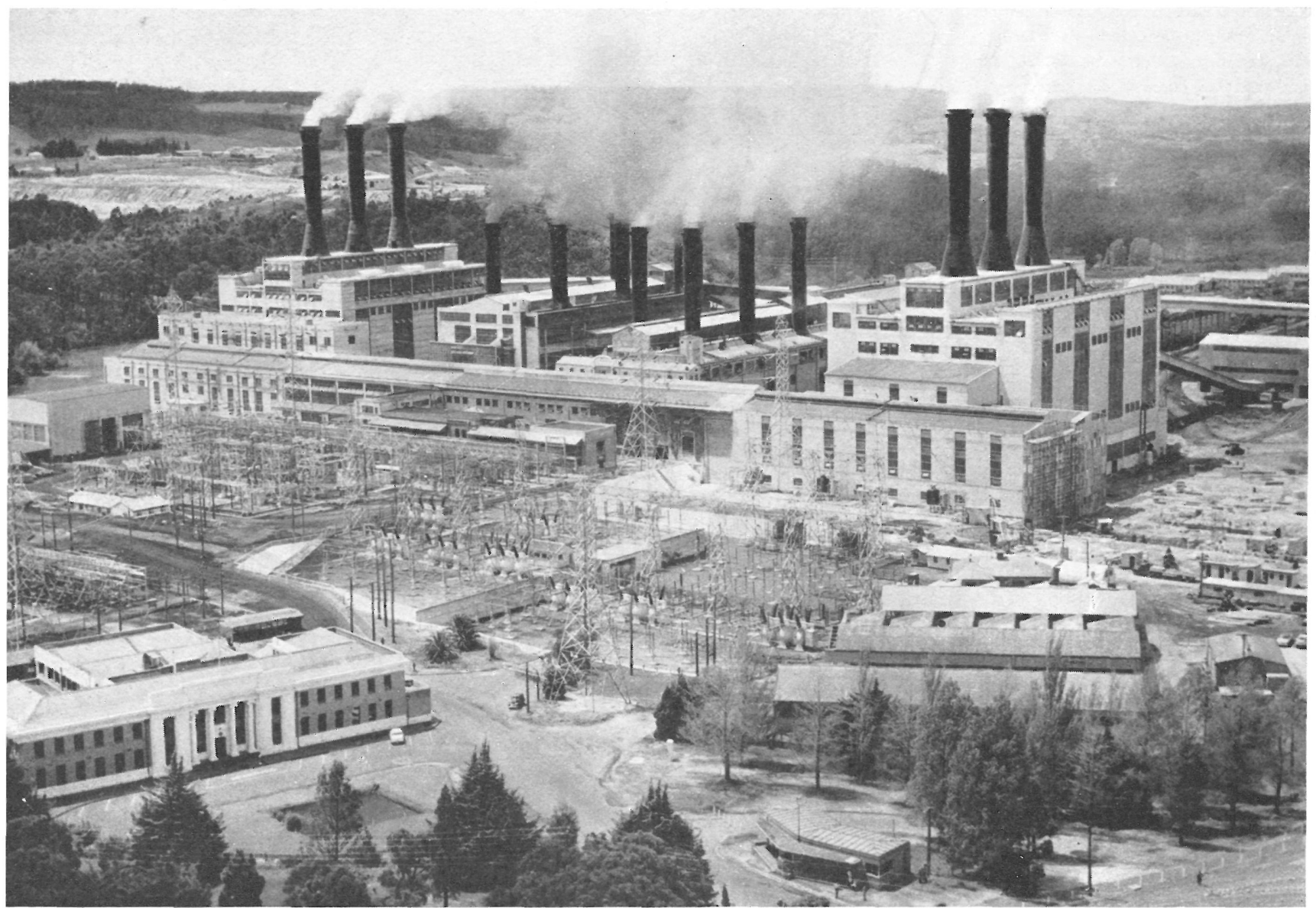

Este basto depósito de carbón pardo constituye un asombro geológico, puesto que es carbón terciario y se le supone ser residuo de una inmensa vegetación forestal que existió hace unos 20 millones de años. Sin embargo, esta edad es relativamente corta para que permita la calificación geológica corriente de carbón; se le admite como lignito, ya que no es suficientemente vieja ni ha sido sometida a calores o presiones que la transformen en carbón negro ordinario.

Naturalmente, este combustible es de grado inferior y contiene dos tercios de su volumen en agua. Hasta ahora no se conoce que se halla utilizado este combustible para la generación de electricidad o fabricación de riquezas comprimidas. La posibilidad de su utilización deriva de su presencia próxima a la superficie terrestre y a la posibilidad del empleo de maquinaria potente de extracción con la que se logra grandes rendimientos mecánicos.

Esta capa carbonífera yace bajo otra de arena y arcilla de escasa potencia. Debajo de este terreno de cobertura se halla una capa media de $60 \mathrm{~m}$ de potencia. Actualmente, se llevan extraídas más de 100 millones de toneladas, pero se cree que todavía existen, por lo menos, otros 50 millones; todos explotables a cielo abierto. Una cubicación de la cuenca hace estimar su contenido en 20.000 millones de toneladas depositadas en el valle de Latrobe.

\section{Explotación}

Los terrenos que cubren la capa carbonífera se excavan mediante potentísimas dragas que limpian un volumen anual del orden de $3.500 .000 \mathrm{~m}^{3}$. Todo este escombro se transporta por medio de trenes arrastrados por locomotoras eléctricas y sirve de relleno de las zonas explotadas.

Una vez limpia la capa de su montera, otras grúas tipo draga se encargan de la explotación de la capa. Las dragas empleadas son de dos tipos: de cadena de cangilones, y de disco con cangilones en rosario. 


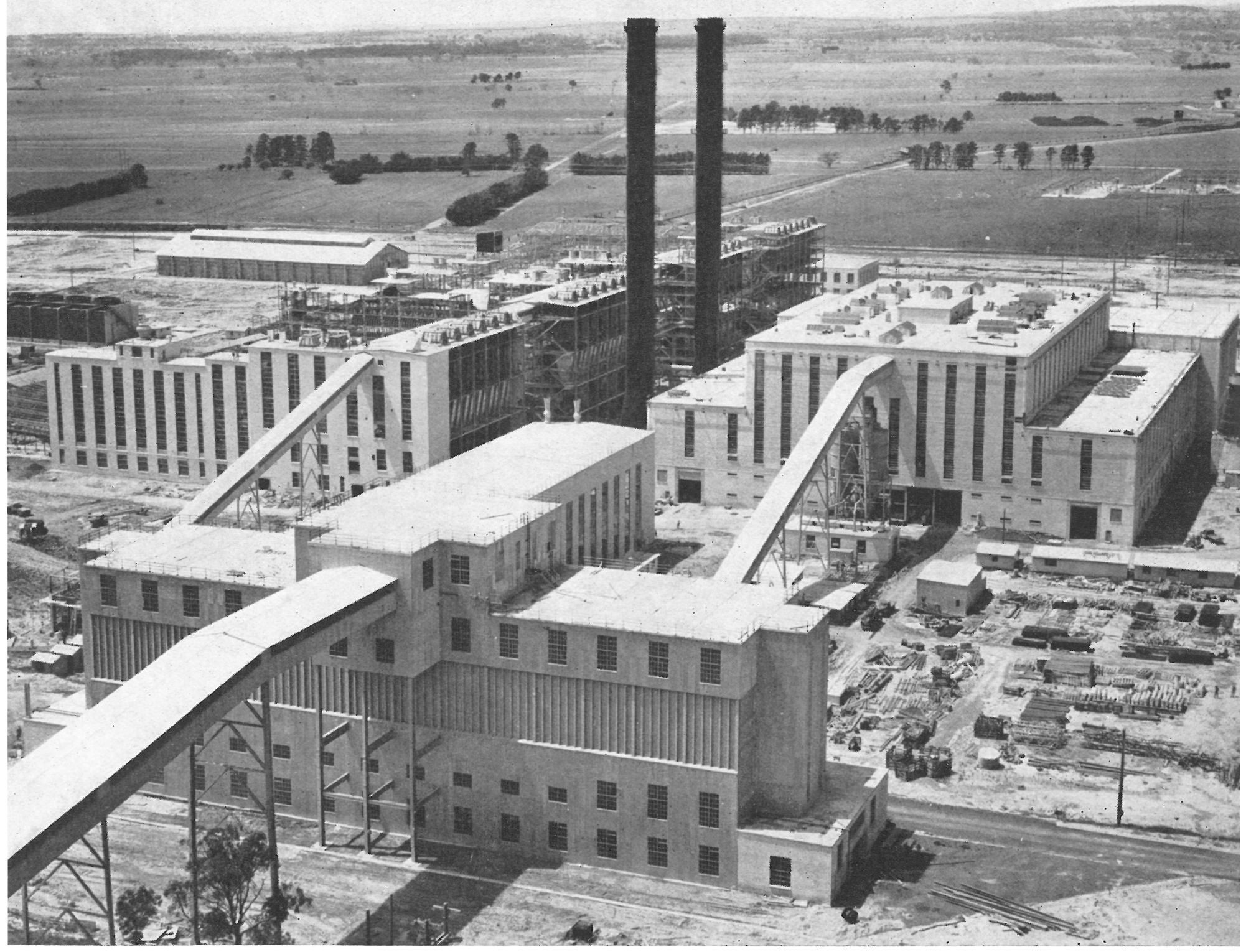

La draga de cangilones forma una cadena sinfín que carga los trenes a medida que avanza en su tajo. La draga va provista de disco en rosario y montada sobre tractores Caterpillar, y carga, también simultáneamente, a los vagones que le siguen. La mayor de este tipo de dragas tiene una capacidad horaria de 1.300 toneladas.

Los trenes cargados de carbón, accionados por tracción eléctrica, conducen estos minerales a la central eléctrica o a los talleres de fabricación de riquezas, que se hallan a unos $50 \mathrm{~km}$ de la zona de explotación. Esta explotación es continua, es decir, se realiza durante las veinticuatro horas del día.

\section{Transformación del carbón en vapor}

El carbón se descarga en grandes depósitos de la Central. De estos depósitos el carbón pasa a las trituradoras; recogido después por cintas transportadoras se le conduce a la parte superior de la caldera, de donde parte, por gravedad, para la alimentación de los hogares. La Central consume 5,5 millones de toneladas por año, pero este consumo se incrementará hasta 8 millones cuando el número de hogares aumente de 22 a 34.

El carbón, con dos tercios de su contenido de agua, al entrar en el horno arde eficientemente y sin grandes pérdidas de calor. A partir de cada depósito de la caldera, el carbón húmedo pasa a través de pozos-canaletas provistos de una serie de peldaños colocados al tresbolillo que permiten un continuo flujo lento del carbón, que, en su movimiento descendente, choca con una corriente de gas caliente ascendente que lo deseca antes de llegar en su curso lento al hogar que lo ha de quemar.

Una vez en la parrilla, arde excelentemente, gracias a una fuerte aportación de aire que procede de la parte inferior. Parte de los gases de la combustión escapan por la parte superior del hogar para ir a las canaletas por las cuales desciende el cwrbón de alimentación, y otra parte de los gases se conduce directamente a las cámaras que contienen las tuberías de las calderas tubulares que producen el vapor. 


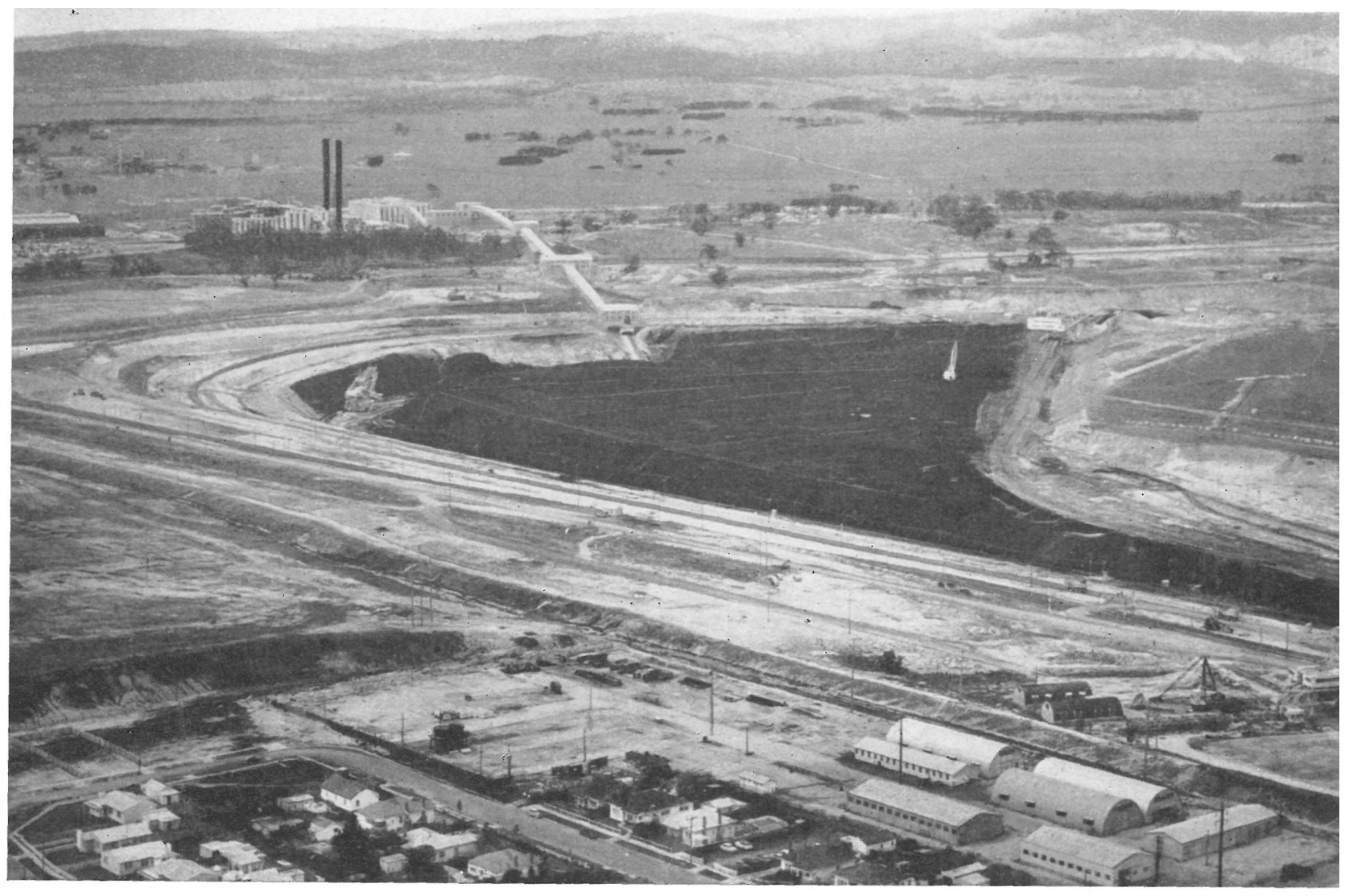

\section{Generación mecánica de energía eléctrica}

El vapor de las calderas se conduce a través de tuberías a las turbinas, donde se transforma en energía mecánica que, a su vez, se transforma en energía eléctrica. El vapor que sale de las turbinas pasa a los condensadores, de donde, transformado en agua, pasa nuevamente a alimentar el ciclo repetido de las calderas. Sólo una pequeña cantidad de agua es requerida de cuando en cuando para contrarrestar las pérdidas; esto, no obstante, se necesitan $45.000 \mathrm{~m}^{3}$ diarios de agua de refrigeración para los condensadores. Este agua procede del río Latrobe.

\section{Capacidad de la central}

En 1924 la Central tenía una capacidad de $62.000 \mathrm{~kW}$ de potencia, para lo cual se contaba con seis generadores. En 1928, con seis generadores, se elevó su capacidad a $75.000 \mathrm{~kW}$ de potencia.

En 1930 se empezó la construcción de una nueva Central, proyecto que se terminó en 1938, con una potencia de $100.000 \mathrm{~kW}$, con lo que se eleva la capacidad total a $175.000 \mathrm{~kW}$.

En 1956 se terminó una tercera Central, también de $100.000 \mathrm{~kW}$ de potencia. Una cuarta Central, también de $100.000 \mathrm{~kW}$ de potencia, se está terminando en la actualidad.

Otra Central, en proyecto, de $240.000 \mathrm{~kW}$ de potencia, elevará la capacidad total de este grupo de Centrales a $615 \mathrm{~kW}$ de potencia, con lo que la explotación será una de las mayores del mundo que transforman el carbón en energía eléctrica a pie de mina.

El coste de generación de energía eléctrica es de los más reducidos en Australia.

La energía eléctrica se genera a $11 \mathrm{kV}$ y se transmite a. $220 \mathrm{kV}$, si bien existen cuatro líneas de $132 \mathrm{kV}$ que la conducen a Melbourne para su ulterior distribución a través de la red estatal.

\section{Taller de briquetas}

Originalmente, toda la producción de carbón se absorbía en la Central de generación de energía eléctrica; sin embargo, la escasez de combustible en Victoria fue motivo de una investigación conducente a determinar la posibilidad del empleo directo de este combustible. Todo ello dio, por consecuencia, en 1921, la instalación de talleres de preparación de briquetas. 
En 1925 la producción de éstas se elevó a 80.000 toneladas por año. Actualmente se producen más de 600.000 toneladas, a razón de más de una tonelada por minuto.

Además de esta producción se mandan 250.000 toneladas a otras Centrales tér micas del Estado, 200.000 a la industria y 100.000 a los gasógenos. Durante la guerra estas riquezas fueron empleadas también para usos domésticos, pero la demanda de este tipo de combustible por las Centrales térmicas fue tan grande y esencial que, actualmente, no se dedica a los usos domésticos.

En unas tres horas y media de tratamiento, la humedad de este combustible desciende considerablemente y se transforma en un sólido moldeado, constituyendo un combustible de alta calidad que arde con poco humo y apenas cenizas. El tratamiento reduce la humedad de un 66 por 100 al 15 por 100 , aumentando el poder calorífico de $1.695 \mathrm{kcal} / \mathrm{kg}$ a 5.280 .

Las briquetas constituyen un potente combustible que quema con muy pocas cenizas y mínimas cantidades de humo.

En estos talleres de fabricación de briquetas se dispone también de una Central térmica auxiliar para la producción de la energía necesaria al taller.

\section{Cuenca minera de Morwell}

Esta cuenca se halla situada a unos $10 \mathrm{~km}$ de la anteriormente descrita, y de ella se ha realizado un proyecto de explotación cuyas características generales son muy similares a las descritas en la cuenca anterior. La sola variante respecto a aquélla estriba en que ocupa lugar prominente la explotación dedicada a la fabricación de briquetas; tal es así, que la transformación del carbón en energía eléctrica se limita a una Central de $90.000 \mathrm{~kW}$ de potencia, mientras que, por el contrario, el carbón dedicado a la fabricación de briquetas se eleva, actualmente, en 1.500.000 toneladas.

Fotografías facilitadas por STATE ELECTRICITY Commision de Victoria
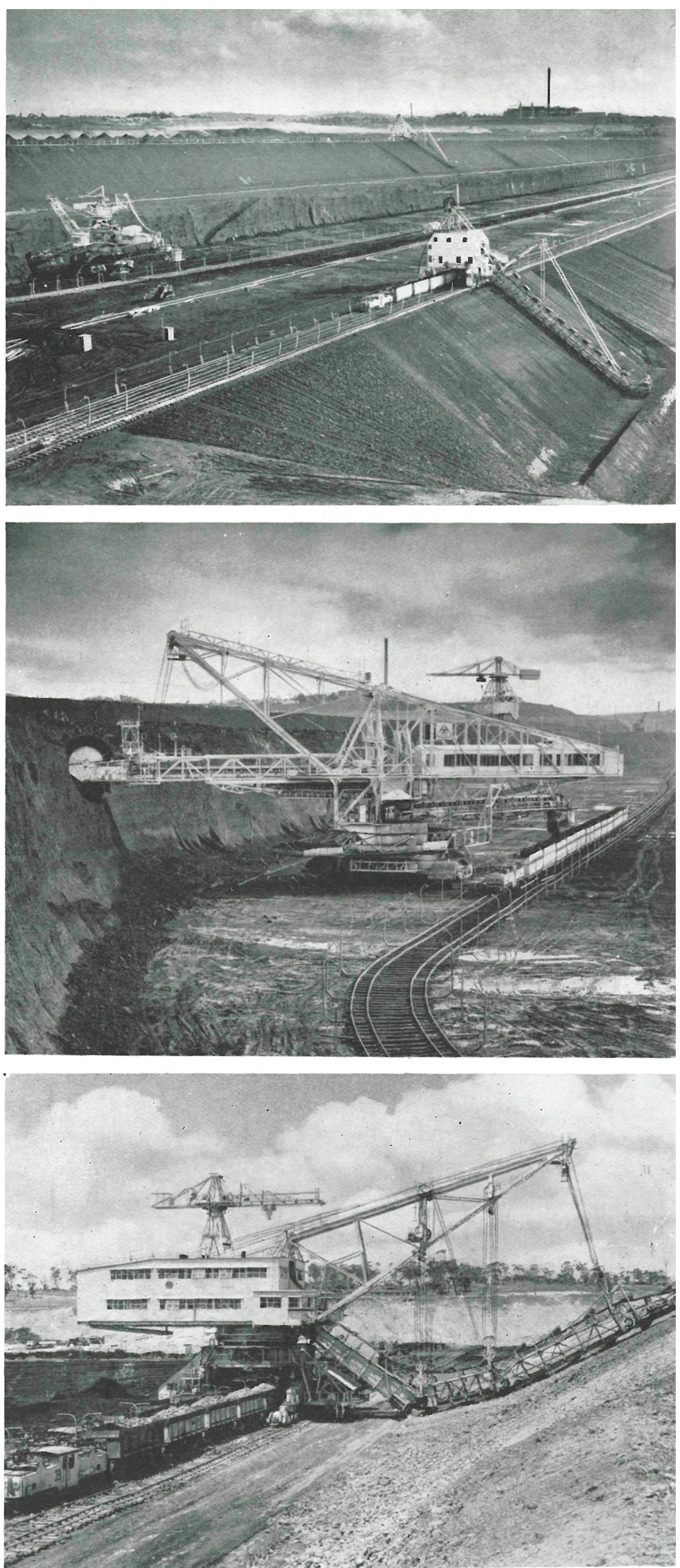